\title{
Small business and its place in promoting sustainable development
}

\author{
Elena Korneeva ${ }^{1,2 *}$, Natalia Skornichenko ${ }^{3 *}$, Tatiana Oruch $^{3 *}$ \\ ${ }^{1}$ Financial University under the Government of the Russian Federation, 49, Leningradsky Prospekt, \\ Moscow, 125993, Russian Federation \\ ${ }^{2}$ Togliatti State University, 14, Belorusskaya St., Togliatti, 445667, Russian Federation \\ ${ }^{3}$ Volga Region State University of Service, 4, Gagarina str., Togliatti, 445017, Russian Federation
}

\begin{abstract}
Sustainable development is becoming a very important issue in the $21^{\text {st }}$ century. Facing global changes such as the global warming, global climate change, as well as other pressing issue, all spheres of economy and social life need to take part in mitigating them and preventing disasters from happening. Our article studies the role of the small business in the above processes and the place of the small business in promoting sustainable development through its actions, public and social awareness and responsibility. We show how even small and medium enterprises can become a decisive power in tackling the climate change and promoting green thinking and sustainable awareness. This can be achieved through enhancing social responsibility of business companies which can greatly contribute to supporting the Sustainable Development Goals (SDG) and promoting sustainable economic growth.
\end{abstract}

\section{Introduction}

In general terms, the objective models of development chosen by individuals, communities and societies for themselves and their communities concern living together on one planet and coexisting in one space and time $[1,2]$. Each community or society has set itself the objective of achieving the objectives of the development model it chooses, taking into account the needs of its citizens and the social and economic conditions of that community, community and society. At the operational level, social sustainability results from actions in key thematic areas that cover the social sphere of individuals and society, from capacity building and capacity development to environmental and spatial inequality. Indeed, the term "social sustainability" and its contributions include a shared enthusiasm for sustainable development and a commitment to social and economic sustainability $[3,4]$. New issues of sustainability, such as climate change, environmental degradation and human rights violations, as well as economic and social inequality and poverty are becoming more pressing with each year. As Nobel laureate Amartya Sen reminded us, "social sustainability" is about taking into account the human aspects of development in everything, including the economy, as part of a holistic approach to economic and social development, and about not only

\footnotetext{
*Corresponding author: korneeva1207@yandex.ru
} 
economic sustainability, but also the need to take into account the humanitarian aspects of development $[5,6]$.

The concept of "social sustainability" can be called unfair because it focuses on economic sustainability, but not on social justice, which relates to the fairness of all people. There are, in fact, other aspects of economic and social development which, significantly, also belong to the area of social sustainability. Sustainable development requires that we are involved in decisions that affect our communities, not only in economic development, but also in social development. Promoting social justice requires progress by countries, organizations and communities whose social well-being can be sustained in the long term. Social sustainability is the ability to achieve lasting good social improvements for all [7]. In addition, social sustainability ensures that the most disadvantaged communities are better off and can maintain their economic and social rights in the long term, regardless of their socioeconomic status. Real sustainability and a true circular economy can only be achieved if the economic, social and environmental aspects of sustainable development - economic growth, economic development and social justice are balanced [8].

Sustainable development is economic development that takes place without the depletion of natural resources. Sustainable development can be promoted including the tripartite partnership with such international powerful organizations as the World Bank, the International Monetary Fund, and, for example, the European Union, which in turn include tripartite partnerships with governments, NGOs, the private sector, and civil society. Such partnerships establish the relationship between economic and social development in the context of sustainable development. Sustainable development is called a "sustainable development society" and is linked to economic, social, environmental and cultural development, as well as the development of a sustainable economy and society [9]. The agreements can be translated into concrete actions with tangible results and we are making progress in implementing these goals in line with the United Nations Sustainable Development Goals. The objectives include economic, social, environmental, health and social development, as well as economic development. Innovative technologies and creative ideas are brought into play to capture an expanded range of values and disciplines. It is essentially considered development that meets the needs of the present without affecting the capabilities of future generations. Sustainable development requires improving the quality of life for all by improving access to health, education, employment, housing, health care and other basic services $[10,11]$.

Today's interconnected global economic system requires an integrated approach to promoting responsible, long-term growth, to ensure that no nation or community is left behind. To preserve our environmental heritage and natural resources for future generations and to preserve natural habitats, economically viable solutions need to be developed to reduce resource consumption, stop pollution and preserve natural habitats in line with the objectives of sustainable development. People worldwide need access to clean water, clean air, clean drinking water and healthy food. This includes the use of renewable energy sources such as wind, solar and hydro power, as well as the development of sustainable agriculture. Each of these pieces is part of the puzzle of a sustainable society, as they are fundamental components of daily life. Sustainable development is the process of thinking, planning and implementing ways to achieve development that is economically, socially and ecologically sustainable. This represents the need to develop a number of ways in which development can be achieved through the use of renewable energy, sustainable agriculture and sustainable water and energy sources. A second, more recent approach suggests that the area of sustainability is social in nature, including environmental, economic, political, and cultural sustainability. While the ecological sphere defines the embedding of humans in the environment, the areas of social sustainability depend on relationships between the social and the natural. Social sustainability is achieved by actively supporting the development of healthy communities 
that are worth living in, and that create a sustainable environment for human health, wellbeing and economic prosperity.

Our article aims at assessing the place and the role of the small business in fostering and promoting sustainable development. We show that small business companies might be as effective as large corporations when practicing corporate social responsibility and playing by the rules of sustainable economy.

\section{Sustainable development and small business}

Sustainable development truly penetrates all spheres of economy and social life. For example, inclusive companies can appeal to low-income markets while generating reasonable profits and having a tangible impact on development. The question is how can small businesses contribute to these ambitious development goals and remain financially sustainable? [12]. The engagement can be transformative and put the world on a path to inclusive, sustainable, and resilient development. Sustainable supply chains ensure that business companies are offered greater opportunities to innovate in new markets and open them up to gain a competitive advantage in international trade. We need to be able to bridge the gap between the product demand, which meets the needs of people in poverty, and the supply chain. New markets open up new business opportunities as we are ultimately the key to the business growth and success. Connecting to these goals would save many small and medium enterprises (SMEs) time and money, improve their brand image, build resilience to uncertainty and save time, money and time for all SMEs involved. It is more than just the responsibility of an SME owner to build a business to shape the economic, social and environmental sustainability that prevails in the world, and it is now her or his own social responsibility as a citizen and an entrepreneur [13].

Half of small businesses consider it important to lead the company into a sustainable future without even thinking about it. For example, Nordic companies with 0-19\% employees (in fact, SMEs) have difficulty understanding the governance part of ESG, especially when they come across governance parts of it [14]. This is due to the fact that in the Nordic countries sustainable development became a part of the primary school curricula and is accompanying people all their lives. Small businesses employ up to $90 \%$ of workers in developing countries, so it is not difficult to see how important it is for growing companies to participate in the agenda [15]. Employees of small and medium-sized enterprises often feel strongly about the sustainability, and some say that sustainability is a moral imperative. If one is a leader who wants to improve her or his environment, friendly efforts or an employee who wants to motivate her or his team, there are steps to help to create a sustainability plan for any SME. This can make a difference when it comes to helping our planet. One can start by creating a "sustainability plan" that guides her or his activities and outlines the goals and future plans.

The good news is that there is growing evidence, from the organizations such as the United States Environmental Protection Agency (EPA), that provide certified embedded systems, that reducing one's SME's carbon footprint can also help improve the outcome [16]. It is often said that in the $21^{\text {st }}$ century, SME customers are increasingly committed to sustainability. Thence, SMEs that apply sustainable business practices have increased the number of employees with at least two years of experience in sustainability and have reduced costs [17]. The benefits of integrating sustainability into a company's core business strategy and reporting on it can more than offset the reduced risk of not being able to achieve any company's sustainability goals in the next five to ten years. Sustainable Business and Sustainability Development in Small Business (SMP) provides university research on the impact of sustainability on small businesses and sustainability development. It also becomes apparent that SMEs can also work together to remove obstacles to achieving environmental 
and economic sustainability by learning and exchanging ideas for sustainable businesses [18]. Development of practical business strategies to promote the environmental, economic and sustainability of existing and new companies and organisations, as well as development of tools for success in the emerging sustainable economy. Several recent studies on corporate citizenship found that over two-thirds of millennials believe that the private sector has a very important role to play in achieving global goals to which companies of all sizes can contribute [19]. The Sustainable Development Goals (SDGs) are very important in the above context. It is a set of 17 "global goals" led by the United Nations to change the world around a common agenda for sustainable development. These objectives provide a framework for formulating a global vision for the future of the global economy and the development of sustainable economies.

\section{Social responsibility for sustainable development}

As it has been already noted above, sustainable development and corporate social responsibility are closely interlinked business concepts that have greatly influenced corporate governance in the early $21^{\text {st }}$ century [20]. Socially responsible companies conserve the ecological resources that are crucial for future generations. Corporate Social Responsibility (CSR) means that corporate and environmental responsibility must be reconciled with the return to communities that support business and long-term business success [21, 22]. The development of corporate social responsibility has been driven in part by increasing consumer social awareness and accountability expectations. Each of the four pillars of corporate sustainability has a direct impact on the long-term sustainability of a company's business model and operations. In recent years, there has been a shift away from traditional growth, profit, and maximization models to a more sustainable business model. The term "paradigm" is used because corporate sustainability is a combination of the four pillars of corporate social responsibility (CSR) and sustainability management. This is an evolving concept that managers have embraced as an alternative to the traditional model of "growth" and "profit maximization," according to a recent report by the Centre for Sustainable Business. Sustainable development is a comprehensive dialectical concept that balances the need for economic growth with environmental protection and social justice. A glance at the literature suggests that the concept of sustainability of companies takes up elements of established concepts. Awareness of the importance of business growth and profitability requires companies to adopt sustainable development strategies, especially those related to environmental sustainability, human rights, social justice, and economic development [23].

In recent years, big business has joined the ranks of development agencies and actors involved in promoting sustainable development. The term was popularized in a report by the World Commission on Environment and Development (WCEC). The situation that is developing is in stark contrast to the past, when big business was less concerned about the environment and more concerned about the welfare of its employees. The growing attachment of senior citizens and the emergence of a new generation of leaders suggest that all divisions are beginning to reshape their relationships with both the environment and their diverse stakeholders. A closer look at the reasons why these sectors and companies are changing shows that the answer has less to do with new ethical concerns that have been found than with changing the nature of their business model. These include so-called win-win opportunities for improved competitive advantage, such as the way production and marketing are organized globally, and new business models.

Although such drivers could encourage companies to focus more on environmental and social concerns, we argue that this process of change is likely to remain fairly fragmented and unevenly distributed across companies, countries, and sectors. As millennials and Gen$\mathrm{Z}$ move into the investor space occupied by Gen-X and boomers, corporate social 
responsibility for securing investment is likely to become even more important. Companies need CSR plans that are focused on longevity, flexibility and responsiveness. There is a clear need to strengthen trends in corporate environmental or social responsibility so that companies can make more meaningful contributions to sustainable development. When different business units have different priorities and objectives that may be aligned, companies may have difficulty getting everyone on the same page. It is vital that companies form a united front in their positions on political, environmental and social issues. Social responsibility can be as simple as applying soft legal principles to promote universal ethical standards in the relationship between private and public enterprises. A unified approach to corporate social responsibility for sustainable development can help ensure the long-term sustainability of the global economy and the future of our planet.

This is also called corporate social responsibility, and refers to a form of self-regulation that integrates various disciplines, including business ethics, human rights, social justice, environmental sustainability and corporate governance. You can donate money, strive to reduce your environmental footprint, implement fair hiring practices, and only work with suppliers with similar values. One can see that the term "Corporate Social Responsibility" is very broad and complex and has different meanings. According to UNIDO, CSR is a form of self-regulation that integrates social and environmental concerns and is seen as a way for companies to achieve a balance between economic, environmental and social needs. Companies take on activities with the aim of the welfare of society, but they have a different meaning. The economic, legal and ethical responsibility of a company is the value it creates for society and for various stakeholders, including its human resources. Many commentators have argued that a CSR agenda has the potential to bring businesses to businesses. In addition, it might be that achieving leadership in business unit is becoming crucial for the success of the Corporate Social Responsibility agenda for sustainable development.

\section{Conclusions}

Therefore, it is apparent that sustainable development is required to achieve a prosperous, inclusive and environmentally sustainable society and to reach economic, social, cultural, environmental and social justice and economic growth. The global economy has created great wealth and technological miracles, but it has also created a society deeply divided between the haves and have-nots - an economy that has destroyed the natural environment and even threatened humanity in order to spur economic growth. The basic idea of sustainable development is that economic growth is not enough for human well-being. It makes no sense to promote an economy in which the poor are harmed by the exploitation of the rich and which threatens the environment, human health and the livelihoods of millions of people, especially in poor countries.

The sustainability of an economy depends on the introduction of appropriate production, distribution, and consumption to promote environmental sustainability, as well as on economic growth. This is why small business enterprises that often constitute the backbone of any economy (in fact making up to two-thirds of all enterprises in some economies, such as, for example, in Southern European countries) should adapt this concept and embed it into their daily functioning.

In addition, everyone has to understand that sustainable development is not only understood from the point of view of economic development, but also in the context of social and environmental development. This has become the core of mainstream sustainability thinking and a key element of the Brundtland report's analysis. The importance of integrating the social dimension has been recognised, but what is its role in defining sustainable development? It builds on indicators developed since 1996, which focus primarily on economic and environmental interactions. This work reflects a broader catalogue of literature 
that takes into account sustainable development indicators that use the three pillars that seem to be building over time. The hypothetical case mentioned above illustrates the importance of the integration of three interrelated areas of sustainability in the concept of sustainable development and their role in the development of sustainable development agenda. This example may be overly simplistic, but it contextualizes how economic, social, and environmental sustainability substrates can interrelate and promote sustainable business and balanced economic growth.

\section{References}

1. B. Singh, M. Keitsch, M. Shrestha, Sustainable Development, 27(2), 237-244 (2019)

2. E. Tarkhanova, Terra Economicus, 16(2), 75-82

3. W. Strielkowski, E. Lisin, E. Astachova, Entrepreneurship and Sustainability Issues, 4(4), 591-600 (2017)

4. V. Amrutha, S. Geetha, Journal of Cleaner Production, 247, 119131 (2020)

5. W. Holford, Futures, 105, 143-154 (2019)

6. V. Ivlev, M. Ivleva, International Conference on Contemporary Education, Social Sciences and Ecological Studies, 869-873 (2018)

7. J. Fleetwood, Sustainability, 12(12), 5027 (2020)

8. V. Panchenko, Y. Harust, Y. Us, O. Korobets, V. Pavlyk, Marketing and Management of Innovations, 1, 256-264 (2020)

9. H. Kopnina, Education Sciences, 10(10), 261 (2020)

10. W. Leal Filho, S. Tripathi, J. Andrade Guerra, R. Giné-Garriga, V. Orlovic Lovren, J. Willats, International Journal of Sustainable Development \& World Ecology, 26(2), 179190 (2019)

11. E. Lisin, D. Shuvalova, I. Volkova, W. Strielkowski, Sustainability, 10(4), 1111 (2018)

12. J. Rendtorff, Local Economy, 34(6), 510-524 (2019)

13. D. Ortiz-Avram, J. Domnanovich, C. Kronenberg, M. Scholz, Journal of Cleaner Production, 201, 254-271 (2018)

14. S. Gillan, A. Koch, L. Starks, Journal of Corporate Finance, 101889 (2021)

15. S. Raza, M. Minai, A. Zain, T. Tariq, F. Khuwaja, International Journal of Entrepreneurship, 22(4), 1-13 (2018)

16. G. Wu, Corporate Social Responsibility and Environmental Management, 24(6), 661675 (2017)

17. M. Kimanzi, V. Gamede, International Journal of Economics and Finance, 12(2), 453$468(2020)$

18. S. Kraus, J. Burtscher, T. Niemand, N. Roig-Tierno, P. Syrjä, Sustainability, 9(10), 1828 (2017)

19. S. Ghosh, J. Rajan, International Journal of Sustainable Development \& World Ecology, 26(4), 344-353 (2019)

20. A. Scherer, C. Voegtlin, Academy of Management Perspectives, 34(2), 182-208 (2020)

21. J. Lu, L. Ren, J. Qiao, S. Yao, W. Strielkowski, J. Streimikis, Sustainability, 11(15), 4128 (2019)

22. G. Barauskaite, D. Streimikiene, Corporate Social Responsibility and Environmental Management, 28(1), 278-287 (2021)

23. A. Androniceanu, Amfiteatru Economic, 21(52), 503-519 (2019) 